\title{
RAPID ENZYMATIC METHOD FOR THE DETERMINATION OF PHOSPHORYL CHOLINE USING THE FLUORESCENCE OF THE ENZYME CHOLINE OXIDASE. SEQUENTIAL DETERMINATION OF CHOLINE AND PHOSPHORYLCHOLINE IN MILK POWDER FOR CHILDREN.
}

Isabel Sanz-Vicente ${ }^{a^{*}}$, María Pilar Lapiezaa,b, Vicente L. Cebollab and Javier Galbána

aAnalytical Biosensors Group, Analytical Chemistry Department, Faculty of Sciences, Aragon Institute of Nanoscience, University of Zaragoza, 50009-Zaragoza, Spain.

b Instituto de Carboquímica (ICB), Consejo Superior de Investigaciones Científicas (CSIC), C/ Miguel Luesma 4, 50018- Zaragoza ,Spain.

*Tel.: 34976762512; fax: 34976761292; e-mail address: isasanz@unizar.es (I. SanzVicente

\section{Abstract}

In this paper we present a rapid method for determining phosphorylcholine (ChoP). ChoP was first hydrolyzed by the enzyme alkaline phosphatase (AP); the choline formed was then submitted to a reaction with Choline Oxidase (ChOx). Both reactions were carried out simultaneously, in the same test without previous steps of incubation. The analytical signals used were the intrinsic fluorescence of $\mathrm{ChOx}$ due to $\mathrm{FAD}$ and that corresponding to a fluorescein derivative bonded to $\mathrm{ChOx}(\mathrm{ChOx}-\mathrm{FS})$; both can be related with the concentration of ChoP. Once the conditions were optimized, the response range for ChoP was $5.2 \cdot 10^{-7}-1.0 \cdot 10^{-5} \mathrm{M}$ using the peak area as the analytical parameter with a precision of about $4 \%$ (RSD) at both ChOx and ChOx-FS wavelengths.

In the experimental conditions found, it was also possible to determine free choline (Ch) with figures of merit similar to those obtained for ChoP. These results have made possible the sequential determination of $\mathrm{Ch}$ and $\mathrm{ChoP}$ in milk powder, using only one aliquot of the mixture, with good results. The recoveries obtained for both analytes were close to $100 \%$.

The method is rapid because an incubation step is not necessary. Moreover, the enzymatic reaction is autoindicating and thus the additional detection step required by other published enzymatic methods is avoided. 
Keyword: fluorescence, choline oxidase, free choline, phosphorylcholine, plate reader

\section{Introduction}

Phospholipids are the primary components of cell membranes, controlling the transfer of substances to the interior or exterior of the cell. They are in fact a mixture of different families, those containing choline (Ch) being the majority. Phosphatidylcholine (PC) is one of the most interesting of these components [1-3]. A by-product of PC is choline phosphate (ChoP), also called phosphorylcholine, formed by the action of the enzyme Phospholipase $\mathrm{C}$ on PC or from the breakdown of sphingolipids (sphingomyelin) by sphingomyelinase $[4,5]$.

There has been a growing interest in $\mathrm{ChoP}$ in recent years. It is used as a coating for lenses [6,7] and, because of its biocompatibility, it is the basis of polymers used in the manufacture of coronary stents [8-11] and drug-eluting stents [12]. In addition, ChoP, like other phospholipids containing choline, is a component found in many foods [13] (acting as a Ch source for the body), especially milk. Because it is an essential nutrient for brain development [14], the American Academy of Pediatrics (AAP) [15] has recommended that infant formulas contain at least $7 \mathrm{mg}$ of choline $/ 100 \mathrm{Kcal}(0.6 \mu \mathrm{mol} / \mathrm{Kcal})$; consequently, Ch, ChoP and other phospholipids are usually determined in this kind of sample [16]. The choline content differs depending on the commercial source. In general, the total choline concentration values range from 31.1 to $227.0 \cdot 10^{-5} \mathrm{M}$ where free $\mathrm{Ch}$ is $4.3 \cdot 10^{-5}-72.3 \cdot 10^{-5}$ $\mathrm{M}$ and $\mathrm{ChoP}$ is up to $83.6 \cdot 10^{-5} \mathrm{M}$.

Several analytical methodologies have been proposed for $\mathrm{Ch}$ and $\mathrm{ChoP}$ determination. Phillips [17] recently reviewed the analytical methods used for the determination of phospholipids containing $\mathrm{Ch}$. Traditionally, the determination of phospholipids and consequently ChoP has been carried out using separation techniques [18] which require various steps in order to isolate both water-soluble compounds (Ch, ChoP) from the hydrophobic compounds (PC, SM) prior to their determination by GC-MS or LC-MS, among others [19-23]. In the last few years new alternatives have emerged. For example, Nzai et al. [24] have developed a simple and rapid method based on FTIR to determine the total phospholipid content in vegetable oil. One of the most interesting methods is the use of P-31 NMR Spectroscopy [25]. This is based on the different chemical shift of the $P$ atom in each phospholipid giving a NMR spectrum with the signal corresponding to the different phospholipids separated. The technique has low sensitivity 
but is non-destructive, so it has been applied for determining phospholipids in several samples, for example olive oil.

For routine control, enzymatic methods are one of the most interesting options. Ch is usually determined by the enzymatic reaction with Choline Oxidase (ChOx). This enzyme catalyzes the substrate oxidation by oxygen in a two-step process, according to:

$$
\begin{aligned}
& \mathrm{Ch}+\mathrm{O}_{2} \stackrel{\mathrm{ChOx}}{\longrightarrow} \mathrm{BA}+\mathrm{H}_{2} \mathrm{O}_{2} \\
& \mathrm{BA}+\mathrm{O}_{2} \stackrel{\mathrm{ChOx}}{\longrightarrow} \mathrm{GB}+\mathrm{H}_{2} \mathrm{O}_{2}
\end{aligned}
$$

BA and GB being Glycine Betaine aldehyde and Glycine Betaine, respectively. The $\mathrm{H}_{2} \mathrm{O}_{2}$ is then submitted to a conventional second reaction involving a chromophore or a fluorophore. The enzymatic determination of ChoP $[26,27]$ is based on the action of alkaline phosphatase (AP) for obtaining $\mathrm{Ch}$.

$$
\mathrm{ChoP}+\mathrm{H}_{2} \mathrm{O} \longrightarrow \mathrm{AP} \longrightarrow \mathrm{Ch}+\text { Phosphate }
$$

Thus there are two alternatives depending on which product is determined: Ch by using (1) or phosphate with molybdate in the presence of a reducer, such as hydroquinone [28]. These methods have also been applied in flow analysis [29]: free $\mathrm{Ch}$ and $\mathrm{Ch}+\mathrm{ChoP}$ are determined, ChoP being calculated as a difference. Similar methodologies have also been used for phospholipids.

Enzymatic methods generally give good results, but they are time-consuming (incubation steps are necessary) and not fully reversible. These problems can be overcome by measuring the enzyme fluorescence changes which can be observed during reaction using oxidation reactions catalysed by flavoenzymes [30] and other enzymes $[31,32]$. The mechanism by which flavoenzymes catalyze the oxidation of substrates can be summarized as follows:

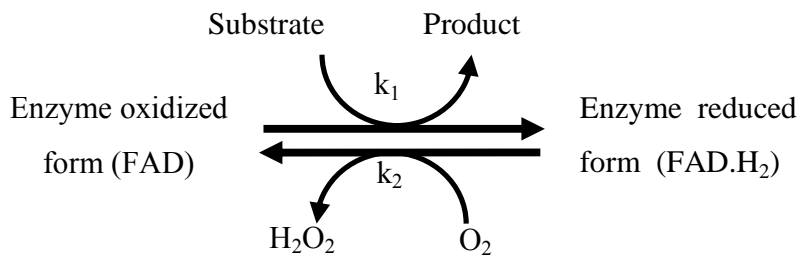


As noted, the flavin group of the enzyme oxidizes the substrate to the product and it becomes reduced to FAD. $\mathrm{H}_{2}$; then, the oxygen regenerates the $F A D$ and $\mathrm{H}_{2} \mathrm{O}_{2}$ is simultaneously formed. This reaction can be followed using three alternatives [33]: A) flavin fluorescence, since both FAD and FAD. $\mathrm{H}_{2}$ have different fluorescence properties, the oxidized forms being more fluorescent than the reduced; B) tryptophan (Trp) fluorescence, due to an energy transfer mechanism with FAD, the fluorescence of the Trp also changes during the enzymatic reaction; $\mathrm{C}$ ) probe fluorescence; some fluorophores linked to the enzyme, such as FS, also modify their fluorescence during the reaction. In this context, ChOx fluorescence has previously been used for determining Ch using alternatives $B$ and C [34] at tryptophan and FS wavelengths, respectively.

In this paper we describe a method for ChoP determination linking reactions (1) and (2) in the same test and measuring the FAD or the FS fluorescence. The method has been applied to the sequential determination of $\mathrm{Ch}$ and $\mathrm{ChoP}$ in a milk sample. This methodology has three additional advantages over previously proposed methods: 1) it does not require the participation or the addition of reagents other than those involved in the reactions, 2) there are not incubation steps so is a rapid method and 3) the enzymes are regenerated during the process so they can be used several times. The process is therefore of great interest for implementation in optical biosensors.

\section{Material and methods}

\subsection{Reagents and solutions}

The buffer solutions were: carbonate solution $0.1 \mathrm{M}, \mathrm{pH} 9.0$ and 10.0, prepared from solid $\mathrm{NaHCO}_{3}$ and $\mathrm{Na}_{2} \mathrm{CO}_{3}$ (Sigma S5761 and 222321). Phosphate solution $0.1 \mathrm{M}$, pH 7.0 and 8.0, prepared from $\mathrm{Na}_{2} \mathrm{HPO}_{4}$ and $\mathrm{NaH}_{2} \mathrm{PO}_{4}$ solids (Panreac 123018.1210 and Sigma S9763).

Enzymes: Alkaline phosphatase (AP) from Calf intestine, $10000 \mathrm{IU} \mathrm{mL} \mathrm{L}^{-1}$ in $10 \mathrm{mM}$ Tris-HCl (Sigma P4978) and finally diluted to $440 \mathrm{IU} \mathrm{mL}^{-1}$ in carbonate buffer at $\mathrm{pH} 9.0$. Choline oxidase (ChOx) from Alcaligenes sp., $13 \mathrm{IU} \mathrm{mg}^{-1}$, lyophilized solid (Sigma C5896), dissolved with carbonate buffer at $\mathrm{pH} 9.0$, until obtaining a solution of $6.6 \mathrm{IU} \mathrm{mL} \mathrm{mL}^{-1}$. Solutions of the enzymes were separated in vials stored in the freezer and kept at a very low temperature (thus preventing denaturation). The fractions to be used were taken daily.

Substrates: Choline phosphate (ChoP), (Sigma P0378). Choline (Ch), 99\%, (Sigma C1879). Stock solutions of ChoP and Ch were prepared daily in buffer solution. 
The labelling agent solution (FS) was prepared by dissolving $1 \mathrm{mg}$ of 6 [Fluorescein-5(6)-carboxamido] hexanoic acid N-hydroxysuccinimide ester (Sigma 46940) in $0.1 \mathrm{~mL}$ of anhydrous dimethyl sulfoxide (Panreac 131954.1611).

\subsection{Labelling procedure}

$1 \mathrm{mg}$ of $\mathrm{ChOx}$ dissolved in $12.8 \mu \mathrm{L} 0.1 \mathrm{M}$ carbonate buffer at $\mathrm{pH} 9.0$ was mixed with $8 \mu \mathrm{L}$ of FS solution in an Eppendorf cap. The mixture was allowed to react in darkness at room temperature for $60 \mathrm{~min}$. The excess of FS was then separated from the ChOx-FS using a home-made exclusion column.

The column consisted of a plastic syringe of $1 \mathrm{~mL}$ capacity, with glass wool placed at the bottom and filled with a solution of Sephadex G-50 (Sigma G-50-150), in water. To compact the enzyme, it remained for $1 \mathrm{~min}$. at $4800 \mathrm{rpm}$ in the centrifuge.

The sample in the Eppendorf cap was collected with the help of a glass syringe, adding $20 \mu \mathrm{L}$ of the mixture at the top of the column. The previously weighed Eppendorf body (which had been separated from the cap) was placed underneath the column. The Eppendorf serves to collect the enzyme fraction linked to the FS, so the excess of labelling is eliminated. The column was placed in the centrifuge, remaining for $5 \mathrm{~min}$. at $4800 \mathrm{rpm}$.

The column was later removed from the centrifuge. A yellow colour strip appeared at the top of the syringe, denoting that the excess of the label had not all been eluted. The FS molecular weight was 586.6 Da, much lower than ChOx 72000. By molecular exclusion, the ChOx enzyme bound to the FS fell by gravity into the Eppendorf. This solution was kept stable for about 4 days at $8^{\circ} \mathrm{C}$.

\subsection{Instruments}

Fluorescence measurements carried out in this work were developed using two kinds of instruments:

Plate reader: The Synergy HT Multi-Mode Microplate Reader, supplied by BioTek, is able to measure fluorescence, absorbance or luminescence. For fluorescence measurements, this instrument consists of a tungsten lamp (as the excitation source), a photomultiplier tube (as the detector) and two filter wheels for excitation and emission wavelength selection ( 380 nm; 420 nm; 440 nm; 485 nm; 508 nm; 530 nm; 560 nm; 620 $\mathrm{nm}$; spectral bandwidths ranging from 20 to $50 \mathrm{~nm}$ ). 
Other instrumental parameters which should be chosen are: sensitivity, illumination mode (top or bottom), and the optical fiber height. Measurements were performed on transparent 96 -well plates. Data were collected using the Gen5 ${ }^{\mathrm{TM}}$ software.

Fluorometer: A Photon Technology International (PTI) Time Master Fluorescence Spectrometer (model TM-2/2003-PTI) was used for performing excitation and fluorescence spectra. In this case, a Xe arc lamp is used as a continuous excitation source. Two monochromators (excitation and emission) allow the measurement wavelength $(\lambda)$ and the excitation and emission slit widths to be selected. The detector is a photomultiplier (PTI814). Measurements were carried out in a $4 \mathrm{~mL}$ Hellma QS 101 quartz cuvette of $1 \mathrm{~cm}$ path length, and the signal was collected with PTI Felix 32 software.

\subsection{Experimental procedure}

\subsubsection{Measurements using the plate reader}

The plate reader was used whenever possible in order to save reagents (the total volume of a well was about $200 \mu \mathrm{L}$ ). The main drawback of this system is that the fluorescence signals during the first seconds of the reaction are lost.

The kinetic measurements consist of fluorescence intensity versus time profiles $(F=f(t))$. Data collection in graphical format minimizes the information loss. To choose the optimal measurement conditions, several tests were performed. Finally, a sensitivity of 100, measurement in Top, a transparent plastic plate and an optical fibre height of $1 \mathrm{~mm}$ were considered as appropriate. The optical filters where chosen taking into account sensitivity and uncertainty (instrumental noise). Finally, the excitation/emission filters for ChOx and ChOx-FS fluorescence measurements used were 420/530 and 440/530, respectively. These experimental conditions were used except where indicated. Most of the measurements were carried out at the intrinsic $\mathrm{ChOx}$ fluorescence.

In a conventional measurement, the necessary amounts of enzymes (usually 50 $\mu \mathrm{L}$ of a $6.6 \mathrm{IU} \mathrm{mL} \mathrm{L}^{-1} \mathrm{ChOx}$ solution and $20 \mu \mathrm{L}$ of a $440 \mathrm{IU} \mathrm{mL}-1$ AP solution) and the buffer solution $(100 \mu \mathrm{L})$ are placed in a well. The plate is placed in the plate reader and the initial fluorescence value (without reaction) is obtained. After $30 \mathrm{~s}$. the plate is taken out, the analyte is injected ( $50 \mu \mathrm{L}$ of an appropriate concentration) and is replaced in order to measure the change in fluorescence during the reaction. It is also necessary to create a specific measurement protocol which includes the measuring features, the time intervals 
for taking the fluorescence values (both baseline and reaction) and the plate input and output sequence for the analyte injection. During the optimization studies, the order of the addition of reagents was modified depending on the parameter to be studied.

In most cases, the gross fluorescence intensity values obtained during the reaction $F_{t}$ were divided by the fluorescence intensity before the reaction $F_{0}$ to obtain the corrected fluorescence $\left(F_{c}\right)$, which is less prone to variations of the enzyme concentration between assays.

\subsubsection{Measurements using the conventional fluorometer}

Most of the spectra were recorded working with a low volume cuvette (about 700 $\mu \mathrm{L}$ solution). The specific experimental conditions used (wavelengths, slits, sensitivity) are indicated throughout the paper.

\subsubsection{Sample preparation and treatment}

About $0.4 \mathrm{~g}$ of milk powder is weighed in a glass bottle and $5 \mathrm{~mL}$ of $\mathrm{pH} 9$ carbonate buffer is added. The bottle is closed and shaken manually to obtain a stable colloidal suspension ( $2 \mathrm{~min}$ ). Any remaining supernatant is removed before proceeding with the treatment.

Several fractions of $1 \mathrm{~mL}$ of this solution are prepared in separate Eppendorf tubes (1.5 $\mathrm{mL}$ of capacity each one). These are centrifuged during $30 \mathrm{~min}$ at $13400 \mathrm{rpm}$. After centrifugation, layers of supernatant are observed at the top and the bottom of the tubes. The retrieved fluid is removed with the help of a plastic syringe (BD Plastipack ${ }^{\mathrm{TM}}, 1 \mathrm{~mL}$ ) with a needle attached (BD Microlance ${ }^{T M} 3$ ). The aqueous phase contains $\mathrm{Ch}$ and $\mathrm{ChoP}$ present in the milk, while phospholipids will be found in the solid phase.

The fluid is filtered through a $0.20 \mu \mathrm{m}$ pore size nylon syringe filter (Albet LabScience) to remove possible traces of supernatant. The final sample fluid containing the analytes of interest (ChoP and $\mathrm{Ch}$ ) is then collected.

\section{Results and discussion.}

\subsection{Analytical signal}

As indicated above, the method is intended to be developed using the plate reader. To choose the filters for excitation and fluorescence, the spectra of $\mathrm{ChOx}$ and ChOx-FS should be considered (see Fig S1 and Fig S2). According to the figures, 420 and $485 \mathrm{~nm}$ should have been chosen as the excitation filters for $\mathrm{ChOx}$ and $\mathrm{ChOx}-\mathrm{FS}$, 
respectively, and $530 \mathrm{~nm}$ as the fluorescence filter in both cases. The spectral bandwidth of the filters were about $20-50 \mathrm{~nm}$ so $440 \mathrm{~nm}$ was chosen as excitation filter for ChOx-FS in order to avoid the interference with emission.

Fig $1 \mathrm{~A}(\mathrm{a})$ shows the corrected fluorescence intensity variation $\left(\mathrm{F}_{\mathrm{c}}\right)$ during the Choline/Choline Oxidase $(\mathrm{Ch} / \mathrm{ChOx})$ reaction working with the plate reader after installing the above-mentioned filters. The initial fluorescence decay is mainly due to the $\mathrm{Ch}$ to $\mathrm{BA}$ oxidation. The later increase appears when the whole BA is oxidized to GB. Since the kinetic of the FAD. $\mathrm{H}_{2}$ formation (forward reaction in (3)) is faster than that of the FAD regeneration (backward reaction) [33], while substrate is present in the solution, the reduced form is the preponderant species and the fluorescence intensity remains low. When the whole substrate ( $C h$ and $B A$ ) has been oxidized, then the FAD becomes the predominant species and the initial fluorescence intensity is recovered.

When $\mathrm{ChOP}$ is the analyte both enzymatic reactions are carried out simultaneously. Initially, choline is not present in the solution. It is slowly liberated during the previous enzymatic hydrolysis with alkaline phosphatase (AP), so the fluorescence versus time variation shows the profile indicated in Fig $1 \mathrm{~A}(\mathrm{~b})$. A comparison between lines $1 \mathrm{~A}(\mathrm{a})$ and $1 \mathrm{~A}(\mathrm{~b})$ reveals that the ChoP hydrolysis is slower than the $\mathrm{Ch}$ to $\mathrm{BA}$ oxidation (the fluorescence decay at the beginning of the reaction is much faster in 1a). As Fig $1 \mathrm{~A}(\mathrm{~b})$ shows, several magnitudes could be used as the analytical parameters for ChoP determination, namely the area of the signal $\left(\mathrm{S}_{\Delta \mathrm{F}}\right)$, the maximum variation of fluorescence intensity $\left(\Delta \mathrm{F}_{\max }\right)$ and the reaction time necessary for the minimum value of the signal to appear $\left(t_{\text {min }}\right)$. The first two were mainly used throughout this work.

When $\mathrm{ChOx}$ is chemically modified with $\mathrm{FS}$, and fluorescence is measured at the FS wavelengths, the fluorescence versus time representation is nearly a mirror image but with positive fluorescence values (Fig $1 \mathrm{~A}(\mathrm{c})$ ) of that shown in Fig $1 \mathrm{~A}(\mathrm{~b})$. This behaviour has been previously explained [34]. Briefly, flavin group of the ChOx absorbs at the same wavelength as FS, so flavin produces an inner filter effect on the FS fluorescence. As FAD presents a molar absorptivity higher than that of FAD. $\mathrm{H}_{2}$, when flavin is in the oxidized form the inner filter effect is higher than in the reduced form; this means that the ChOx-FS fluorescence at the FS wavelengths is higher when the flavin is in the reduced form. Again,

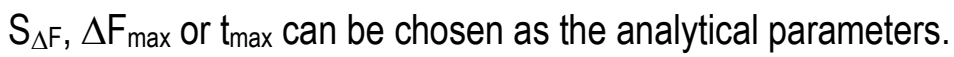




\subsection{Optimization of parameters}

\subsubsection{Enzymes concentration}

From the enzyme kinetic point of view, both $\mathrm{ChOx}$ and $\mathrm{ChOx}-\mathrm{FS}$ behave in a similar way, so the optimization can be carried out using either of them and extrapolating the conclusions to the other enzyme. In this work, the optimization was carried out using ChOx.

Since two enzymatic reactions are involved simultaneously in the method, it is important to clarify in detail the effect of each one on the fluorescence signal. However, it must be taken into account that the goal is to obtain a signal that allows a determination with sufficient sensitivity in a short time; i.e., the objective is to strike a balance between sensitivity and analysis time.

The effect of the alkaline phosphatase (AP) concentration on the ChoP determination was studied. The results obtained working in $\mathrm{S}_{\Delta \mathrm{F}}$ and $\Delta \mathrm{F}_{\max }$ are shown in Fig $2 \mathrm{~A}$, indicating that both analytical signals directly depend on the AP concentration. The increment is sequentially less important as the enzyme concentration increases, so for high concentrations ( $40 \mathrm{IU} \mathrm{mL}-1$ and $64 \mathrm{IU} \mathrm{mL}^{-1}$ ) the results trend to a plateau and nearly null improvements are observed. This indicates that a further increase in the AP concentration would not increase the signal, so $40 \mathrm{IU} \mathrm{mL} \mathrm{m}^{-1}$ was considered as the optimum. The $\mathrm{t}_{\mathrm{min}}$ behaves virtually independently of the enzyme concentration (see Table S1 and profiles in Fig S3).

The effect of the concentration of the enzyme choline oxidase (ChOx) on the determination of ChoP was also studied. Fig 2B shows the results obtained from normalized intensities. These results are better explained after taking into account that the fluorescence of the enzyme is being measured, thus the higher the enzyme concentration, the faster the reaction, so the smaller the area and the $t_{\min }$. The maximum fluorescence variation proved to be independent of the $\mathrm{ChOx}$ concentration, as can be seen in the results shown in Table S2 (and Fig S4). Balancing the reaction time and the signal, it was considered that a ChOx concentration of about $2 \mathrm{IU} \mathrm{mL}^{-1}$ would be a good compromise.

\subsubsection{Working $\mathrm{pH}$}

The activity of both enzymes depends on the $\mathrm{pH}$. Regarding $\mathrm{ChOx}$ [33], for $\mathrm{pH}$ values below 7 no reaction is detected while for $\mathrm{pH}$ values higher than 11 the enzyme denaturation quickly begins; the optimum $\mathrm{pH}$ for $\mathrm{ChOx}$ is 9.5 but it is possible to work in a 
range between 8 and 10. Respecting $\mathrm{AP}$, the enzyme is stable in the $\mathrm{pH}$ range 7.5-11, and the $\mathrm{pH}$ optimum for enzymatic activity is $\mathrm{pH} 8-10$ [35]. In order to optimize the $\mathrm{pH}$ conditions for the ChoP determination, the reaction was performed with four different $\mathrm{pHs}$ $(7,8,9$ and 10$)$. The $F_{c}=f(t)$ profiles obtained are shown in Fig S5 and the results are shown in table 1. No changes in the shape of the fluorescence intensity versus time profiles with $\mathrm{pH}$ variation were observed. As a conclusion, $\mathrm{pH}=9$ was finally chosen as the most suitable for this method.

The composition of the buffer solution also affects the signal obtained. The best results were achieved using a carbonate buffer. Phosphate and TRIS-HCl were also tested but the signal was unstable in both cases.

\subsection{Analytical characteristics for ChoP determination}

In the light of the above considerations, the experimental conditions finally chosen were a $40 \mathrm{IU} \mathrm{mL} \mathrm{AP}^{-1}$ solution, a $1.65 \mathrm{IU} \mathrm{mL}^{-1} \mathrm{ChOx}$ solution and $\mathrm{pH}$ 9. In these conditions the figures of merit of the method were obtained. Fig 1B shows the ChoP calibration study obtained measuring the flavin fluorescence and using the optimum conditions. Table 2 shows the results. Obviously, the methodology is faster measuring the $\Delta F_{\max }$ parameter but the linear range and reproducibility are worse.

A study of the figures of merit was also carried out using the fluorescence of ChOx-FS. The results (also compiled in table 2) were similar to those obtained using ChOx.

\subsection{Ch and ChoP simultaneous determination.}

In many samples containing $\mathrm{ChoP}, \mathrm{Ch}$ is also present as a constituent. Since $\mathrm{Ch}$ also reacts with $\mathrm{ChOx}$, the method described can be adapted for a combined determination of both analytes. Fig 3 shows a $F_{c}=f(t)$ profile obtained when $C h O x-F S$ and AP are sequentially added to a solution containing a $\mathrm{Ch}+\mathrm{ChOP}$ mixture. After $\mathrm{ChOx}-\mathrm{FS}$ addition, only the $\mathrm{Ch}$ present in the solution reacts (first maximum). When the ChOx-FS fluorescence returns to the initial value (which means that the Ch reaction is over), the subsequent addition of AP starts the ChoP reaction, giving the second maximum. From the $\Delta \mathrm{F}_{\max }$ and $\mathrm{S}_{\Delta \mathrm{F}}$, the $\mathrm{Ch}$ and $\mathrm{ChoP}$ concentrations can be determined.

A calibration of $\mathrm{Ch}$ was made in $\mathrm{ChoP}$ determination conditions. The results are shown in Table 2. Complementary assays were carried out and the following conclusions were obtained: 1) the presence of AP or ChoP in solution does not affect the $\mathrm{ChOx}$-Ch 
reaction (Fig S6), and 2) the previous reaction of Choline has no effect on the enzyme kinetics of the ChoP (Fig S7).

\section{5 $\mathrm{Ch}$ and ChoP determination in a milk sample.}

Since no reference material was available, in this work we have applied the methodology described to determine both $\mathrm{Ch}$ and ChoP in infant milk powder.

\subsubsection{Elimination of interference}

Milk is a very complex matrix with large amounts of water, fat, protein, lactose, vitamins and other compounds. Potential hydrophobic interferences can be eliminated after the simple treatment of the sample described in section 2 . The enzymatic reaction assures the specificity of the method. However, some water soluble substances could present fluorescence and potential spectral interferences. The background fluorescence remaining in the aqueous phase was studied. To do this, 3D- excitation-emission-spectra were obtained (containing the spectra of emission fluorescence between 300 and $700 \mathrm{~nm}$, exciting from 280 to $480 \mathrm{~nm}$ wavelengths at intervals of $10 \mathrm{~nm}$ ). The registration is shown in Fig 4. The x-axis represents the excitation wavelengths and y-axis the emission ones. The fluorescence is represented by contour lines in which the intensity colour scales are represented at the right of the graph. Three major peaks can be highlighted. Two of them are located at $\lambda_{\text {exc. }} 380 \mathrm{~nm}, \lambda_{\mathrm{em}} .520 \mathrm{~nm}$, and $\lambda_{\mathrm{exc}} .450 \mathrm{~nm}, \lambda_{\mathrm{em}} .520 \mathrm{~nm}$, respectively. These peaks, which match with those of the FAD, are presumably due to riboflavin present in milk as Vitamin B2. The third peak, prominent for its high intensity fluorescence, is $\lambda_{\text {exc. }} 290 \mathrm{~nm}$, $\lambda_{\mathrm{em}} 340 \mathrm{~nm}$ corresponding to tryptophan (Trp) of amino acids in milk. Rayleigh scattering and its harmonic (white stripes) also appear. 
Several alternatives were tested to eliminate the fluorescence of the riboflavins:

1) by irradiating with UV light (riboflavin could be degraded by radiation), the interference could only be partially reduced;

2) it could be observed that this fluorescence depended on the $\mathrm{pH}$ and composition of the buffer solution influencing the stability of the fluorescence of the milk; if the $\mathrm{pH}$ increases, a decrease in fluorescence is observed, the best results being at $\mathrm{pH} 9$ and $10(\mathrm{pH} \mathrm{7,} \mathrm{8,} 9$ and10 were tested). Since at $\mathrm{pH}=9$ good sensitivity was obtained, this was finally chosen for the determination. Again, the nature of the buffer substantially affected the signal. Different buffers were tested (carbonate, phosphate, Tris-HCl). It was found that the best results were obtained using carbonate buffer.

3) Working with $\mathrm{ChOx}-\mathrm{FS}$ instead of $\mathrm{ChOx}$. ChOx-FS presents a very intense fluorescence which masks the residual fluorescence of the sample. In addition, since kinetic signals are being measured, the residual spectral interference can be corrected by subtraction.

Finally, the spectral interference problem was avoided by combining options 2 (working at $\mathrm{pH}=9$ carbonate) and 3 (using $\mathrm{ChOx}-\mathrm{FS}$ instead of $\mathrm{ChOx}$ ).

After eliminating the background fluorescence, a certain effect of the matrix of the sample on the kinetic of the reaction was observed. This was solved by using the standard addition method.

\subsubsection{Enzymatic determination of $\mathrm{Ch}$ and ChoP in the sample}

To carry out the determination in infant milk formula, the standard addition method was used. The determination was carried out in triplicate. The sample was prepared as described in section 2.4.3, adding both analytes before the separation treatment so that they underwent the same processes as the sample at all times.

The analytical signal selected was the area. The results obtained were $0.157 \pm$ $0.013 \mathrm{mg} / \mathrm{gr}$ of free $\mathrm{Ch}$ and $0.022 \pm 0.002 \mathrm{mg} / \mathrm{gr}$ of ChoP in milk $(\mathrm{n}=3)$, in agreement with results from the literature [16]. A recovery study was also performed. Concentrations of $\mathrm{Ch}$ and ChoP were added to the solution obtained before centrifugation, which were submitted to the described procedure. Recovery of $93 \%$ for Ch and $95 \%$ for ChoP were obtained. 


\section{Conclusions}

The use of combined AP/ChOx linked to the fluorescence of the latter allows the determination of ChoP to be carried out in a short period of time with good sensitivity. Moreover, it has been demonstrated that the simultaneous determination of $\mathrm{Ch}$ and $\mathrm{ChoP}$ can be carried out easily using the intrinsic fluorescence of $\mathrm{ChOx}$ (or the induced ChOx-FS fluorescence). In addition, from the results given in this work it seems clear that plate readers can be conventionally used for developing enzymatic methods based on enzyme fluorescence.

The most important advantages of this method are that it does not require the addition of more reactives than those involved in the reaction, and enzymes are regenerated during the process so that they can therefore be used several times. The possibility of using this method as the basis for optical sensors is currently being studied.

Acknowledgments This work was supported by the Spanish Ministerio de Economía y Competitividad (MINECO) (CTQ 2012-34774) (CTQ 2012-35535), FEDER (EU) (CTQ 200806751 C02-01/BQU) and by the Regional Government of Aragón (DGA) (Support to Research Group E-74). Thanks to Dr. Jesús Martínez de la Fuente for providing the opportunity to use the BioTek Synergy HT Multi-Mode Microplate Reader. 


\section{References}

[1] G.J. Nelson, The phospholipid composition of plasma in various mammalian species, Lipids 2(4) (1967) 323-328.

[2] H. Hidaka, K. Yamauchi, H. Ohta, T. Akamatsu, Specific, rapid, and sensitive enzymatic measurement of sphingomyelin, phosphatidylcholine and lysophosphatidylcholine in serum and lipid extracts, Clin. Biochem. 41(14-15) (2008) 1211 1217.

[3] L. Hodson, C.M. Skeaff, B.A. Fielding, Fatty acid composition of adipose tissue and blood in humans and its use as a biomarker of dietary intake, Prog. Lipid. Res. 47(5) (2008) 348-380.

[4] K.P. Huang, F. Huang, Differential sensitivity of protein kinase $C$ isozymes to phospholipid-induced inactivation, J. Biol. Chem. 265 (1990) 738-744

[5] R. Kolesnick, D.W. Golde, The sphingomyelin pathway in tumor necrosis factor and interleukin-1 signaling, Cell 77(1994) 325-328

[6] S. L. Willis, J. L. Court, R. P. Redman, J.H. Wang, S.M. Leppard, V.J. O’Byrne, S.A. Small, A.L. Lewis, S.A. Jones, P.W. Stratford, A novel phosphorylcholine-coated contact lens for extended wear use, Biomaterials 22(24) (2001) 3261-3272.

[7] L. Selan, S. Palma, G.L. Scoarughi, R. Papa, R. Veeh, D. Di Clemente, M. Artini, Phosphorylcholine impairs susceptibility to biofilm formation of hydrogel contact lenses, Am. J. Ophthalmol. 147(1) (2009) 134-139.

[8] D.M. Whelan, W.J. Van der Giessen, S.C. Krabbendam, E.A. Van Vliet, P.D. Verdouw, P.W. Serruys, H.M. Van Beusekom, Biocompatibility of phosphorylcholine coated stents in normal porcine coronary arteries, Heart 83(3) (2000) 338-345.

[9] N. Hamdan Suleiman, Stents coronarios y prevención de reestenosis: Primera Parte, Medicrit 3(3) (2006) 68-77.

[10] A.L. Lewis, Phosphorylcholine-based polymers and their use in the prevention of biofouling. Colloids Surf. B: Biointerfaces 18(3-4) (2000) 261-275.

[11] J.A. Hayward, D. Chapman, Biomembrane surfaces as models for polymer design: the potential for haemocompatibility, Biomaterials 5(3) (1984) 135-142. 
[12] A.L. Lewis, T.A. Vick, A.C.M. Collias, L.G. Hughes, R.R. Palmer, S.W. Leppard, J.D. Furze, A.S. Taylor, P.W. Stratford, Phosphorylcholine-based polymer coatings for stent drug delivery, J. Mat. Sci.: Mater. Med. 12(10-12) (2001) 865-870.

[13] S.H. Zeisel, M.H. Mar, J.C. Howe, J.M. Holden, Concentrations of cholinecontaining compounds and betaine in common foods, J. Nutr. 133 (2003) 1302-1307.

[14] S.H. Zeisel, Nutritional importance of choline for brain development, J. Am. Coll. Nutr. 23(6) (2004) 621S-626S.

[15] AAP (American Academy of Pediatrics). Pediatric Nutrition Handbook, 2nd ed.; Committee on Nutrition, Academy of Pediatrics: Elk Grove Village, IL, 1985.

[16] Y.O. Ilcol, R. Ozbek, E. Hamurtekin, I.H. Ulus, Choline status in newborns, infants, children, breast-feeding women, breast-fed infants and human breast milk, J. Nutr.

Biochem. 16 (2005) 489-499.

[17] M.M. Philips, Analytical approaches to determination of total choline in foods and dietary supplements, Anal. Bioanal. Chem. 403(2012) 2103-2112

[18] N.U. Olsson, N. Salem, Molecular specie analysis of phospholipids, J. Chromatogr. B 692(2) (1997) 245-256.

[19] P. Donato, F. Cacciola, F. Cichello, M. Russo, P. Dugo, L. Mondello,

Determination of phospholipids in milk samples by means of hydrophilic interaction liquid chromatography coupled to evaporative light scattering and mass spectrometry detection, J. Chromatogr. A 1218(37) (2011) 6476-6482.

[20] Y.Y. Zhao, Y.P. Xiong, J.M. Curtis, Measurement of phospholipids by hydrophilic interaction liquid chromatography coupled to tandem mass spectrometry: The determination of choline containing compounds in foods, J. Chromatogr. A 1218(32) (2011) 5470-5479.

[21] R. Jang, K.H. Kim, S.A. Zaidi, W.J. Cheong, M.H. Moon, Analysis of phospholipids using an open-tubular capillary column with a monolithic layer of molecularly imprinted polymer in capillary electrochromatography-electrospray ionization-tandem mass spectrometry, Electrophor. 32(16) (2011) 2167-2173.

[22] M. Narvaez-Rivas, E. Gallardo, J.J. Ríos, M. León-Camacho, A new highperformance liquid chromatographic method with evaporative light scattering detector for the analysis of phospholipids - application to Iberian pig subcutaneous fat, J. Chromatogr. A 1218(22) (2011) 3453-3458. 
M. Kosicek, S. Kirsch, R. Bene, Z. Trkanjec, M. Titlic, L. Bindila, Nano-HPLC-MS analysis of phospholipids in cerebrospinal fluid of alzheimer's disease patients - a pilot study, Anal. Bioanal. Chem. 398(7-8) (2010) 2929-2937.

[24] J.M. Nzai, A. Proctor, Phospholipids determination in vegetable oil by thin-layer chromatography and imaging densitometry, Food Chem. 63(4) (1998) 571-576.

[25] E. Hatzakis, A. Koidis, D. Boskou, P. Dais, Determination of phospholipids in olive oil by P-31 NMR Spectroscopy, J. Agric. Food Chem. 56(15) (2008) 6232-6240.

[26] E. Pedruzzi, J. Hakim, J.P. Giroud, A. Perianin, Analysis of Choline and Phosphorylcholine content by f-Met-Leu-Phe and Phorbol Myristate Acetate: Contribution of Phospholipase D and C, Cell Signal, 10 (1998) 481-489

[27] A.J. Barak, D.J. Tuma, Determination of Choline, phosphorylcholine and betaine, Methods in Enzymology, 72 (1981) 287-292.

[28] M. Yaqoob, A. Nabi, M. Siddiqui, A. Waseem, A.K. K.Achakzai, A. Saeed, Enzymatic procedures for the determination of phospholipids, J. Chem. Soc. Pakistan 23(3) (2001)171-175.

[29] N. Amini, I. McKelvie, An enzymatic flow analysis method for the determination of phosphatidylcholine in sediment pore waters and extracts, Talanta 66(2) (2005) 445-452.

[30] J. Galbán, Y. Andreu, J. Sierra, S. de Marcos, J.R. Castillo, Intrinsic fluorescence of enzymes and fluorescence of chemically modified enzymes for analytical purposes - A review, Luminiscence. 16(2) (2001) 199-210.

[31] J. Galbán, S. de Marcos, J.R. Castillo, Fluorometric enzymatic determination based on enzyme Cytochrome-B(2) fluorescence, Anal. Chem. 65(21) (1993) 3076-3080.

[32] S. de Marcos, J. Galbán, R. Albajez, J.R. Castillo, Enzymatic determination of ethanol based on the intrinsic fluorescence of alcohol dehydrogenase, Anal. Chim. Acta 343(1-2) (1997) 117-123.

[33] J. Galbán, I. Sanz-Vicente, E. Ortega, M. del Barrio, S. de Marcos, Reagentless fluorescent biosensors based on proteins for continuous monitoring systems, Anal.

Bioanal. Chem. 402(2012) 3039-3054

[34] J. Galbán, O. Sanchez-Monreal, Y. Andreu, S. de Marcos, J.R. Castillo, Choline determination based on the intrinsic and the extrinsic (chemically modified) fluorescence of choline oxidase, Anal. Biochem. 334(2) (2004) 207-215. 
[35] Sigma-Aldrich Co. (2011) Life science, metabolomics, enzyme explorer, analytical enzymes, alkaline phosphatase. Http://www.sigmaaldrich.com. 


\section{Figure Captions}

Fig 1.- A Variation in fluorescence intensity over time during the enzymatic reaction. (a) $[\mathrm{Ch}]=1.0 \cdot 10^{-5} \mathrm{M},[\mathrm{ChOx}]=1.65 \mathrm{IU} \mathrm{mL}^{-1}, \mathrm{pH} 9$ at FAD wavelengths $\left(\lambda_{\text {exc }} .420 \mathrm{~nm}\right.$ and $\lambda_{\mathrm{em}} .530$ $\mathrm{nm}$ ) (b) $[\mathrm{ChOP}]=1.0 \cdot 10^{-5} \mathrm{M},[\mathrm{ChOx}]=1.65 \mathrm{IU} \mathrm{mL}^{-1},[\mathrm{AP}]=40 \mathrm{IU} \mathrm{mL}-1, \mathrm{pH} 9$ at FAD wavelengths $\left(\lambda_{\text {exc. }} 420 \mathrm{~nm}\right.$ and $\left.\lambda_{\text {em }} .530 \mathrm{~nm}\right)$; (c) [ChoP] $=1.0 \cdot 10^{-5} \mathrm{M}$, [ChOx-FS]=1.65 IU $\mathrm{mL}^{-1},[\mathrm{AP}]=40 \mathrm{IU} \mathrm{mL}-1, \mathrm{pH} 9$ at FS wavelengths $\left(\lambda_{\text {exc. }} 440 \mathrm{~nm}\right.$ and $\left.\lambda_{\mathrm{em}} .530 \mathrm{~nm}\right)$. B Choline phosphate calibration study at $F A D$ wavelengths. $[A P]=40 \mathrm{IU} \mathrm{mL} \mathrm{L}^{-1},[\mathrm{ChOx}]=1.65 \mathrm{IU} \mathrm{mL} \mathrm{m}^{-1}$, $\mathrm{pH} 9, \lambda_{\text {exc. }} 420 \mathrm{~nm}$ and $\lambda_{\text {em. }} 530 \mathrm{~nm}$. ChoP concentrations are (in M):
a)blank
b) $5.20 \cdot 10^{-7}$
c) $1.00 \cdot 10^{-6}$
d) $5.20 \cdot 10^{-6}$
e) $1.00 \cdot 10^{-5}$
f) $5.00 \cdot 10^{-5}$
g) $1.00 \cdot 10^{-4}$

Fig 2.- $A$ Influence of $[A P]$ on $S_{\Delta F}\left(\bullet\right.$ and $\Delta F_{\max }(\square)$. [ChOx] $=1.65 \mathrm{IU} \mathrm{mL}^{-1}[\mathrm{ChoP}]=1.0 \cdot 10$ ${ }^{5} \mathrm{M}, \mathrm{pH} 9, \lambda_{\text {exc. }} 420 \mathrm{~nm}$ and $\lambda_{\text {em. }} 530 \mathrm{~nm}$. B Influence of $[\mathrm{ChOx}]$ on $\mathrm{S}_{\Delta \mathrm{F}}\left(\bullet\right.$ )and $\mathrm{t}_{\min }(\boldsymbol{\square})$. $[A P]=32 \mathrm{IU} \mathrm{mL}^{-1}$, [ChoP] $=1.0 \cdot 10^{-5} \mathrm{M}, \mathrm{pH} 9, \lambda_{\text {exc. }} .20 \mathrm{~nm}$ and $\lambda_{\mathrm{em}} .530 \mathrm{~nm}$.

Fig 3.--- Fluorescence intensity variation over time during the sequential enzyme reaction of a sample containing $\mathrm{Ch}$ and ChoP measured at wavelengths of the FS.

$[\mathrm{Ch}]=4.90 \cdot 10^{-5} \mathrm{M},[\mathrm{ChOP}]=2.0 \cdot 10^{-5} \mathrm{M},[\mathrm{ChOx}-\mathrm{FS}]=1.50 \mathrm{IU} \mathrm{mL}^{-1},[\mathrm{AP}]=40 \mathrm{IU} \mathrm{mL}-1, \mathrm{pH} 9$ at FS wavelengths ( $\lambda_{\text {exc. }} .440 \mathrm{~nm}$ and $\lambda_{\mathrm{em}} .530 \mathrm{~nm}$ )

Fig 4.- 3D spectrum of the aqueous fraction of infant milk. Quartz cuvette, $\lambda_{\text {exc. }} 280,290$, 300,310 ...to $480 \mathrm{~nm}$ and $\lambda_{\mathrm{em}} 300-700 \mathrm{~nm}$, width slits $4 \mathrm{~nm}$ (exc.) and $4 \mathrm{~nm}$ (em.) 


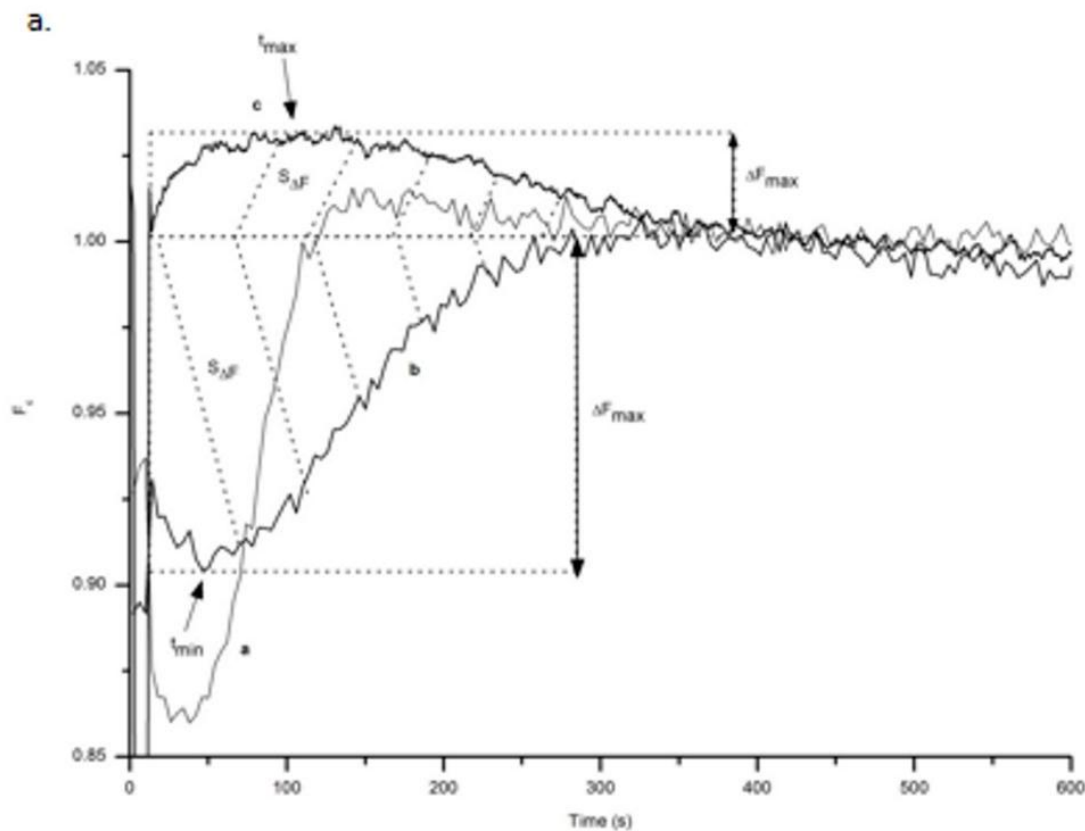

b.

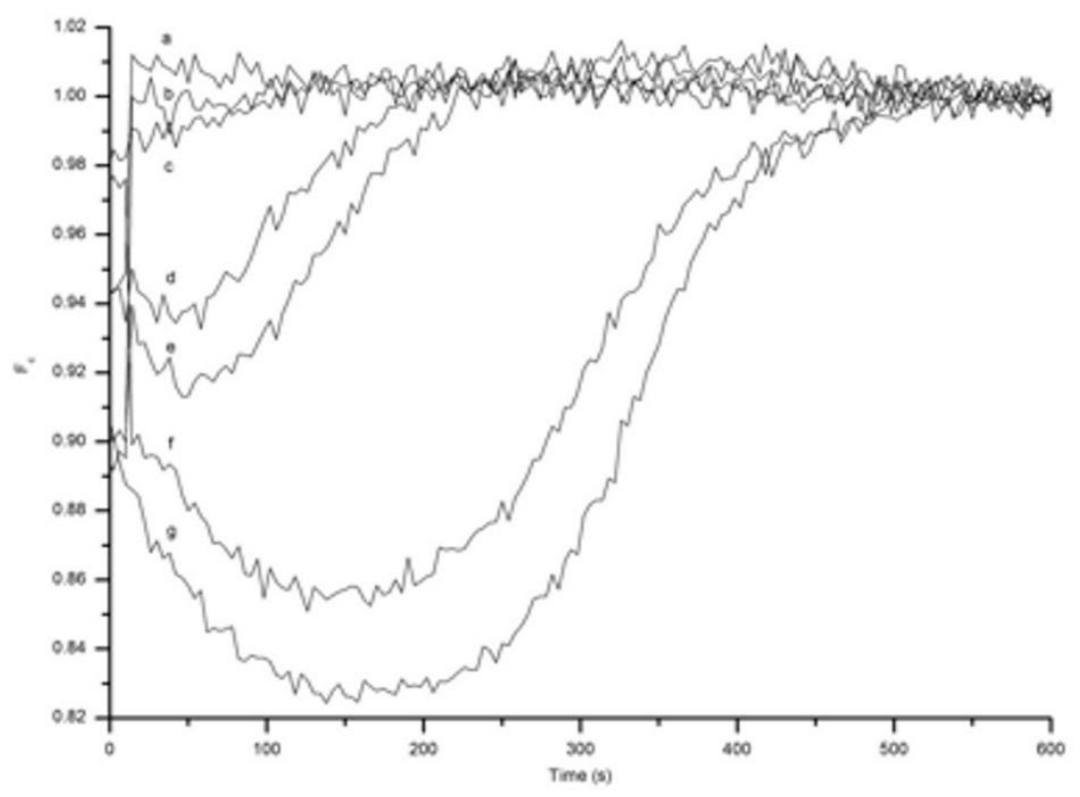

Figure 1 
a.

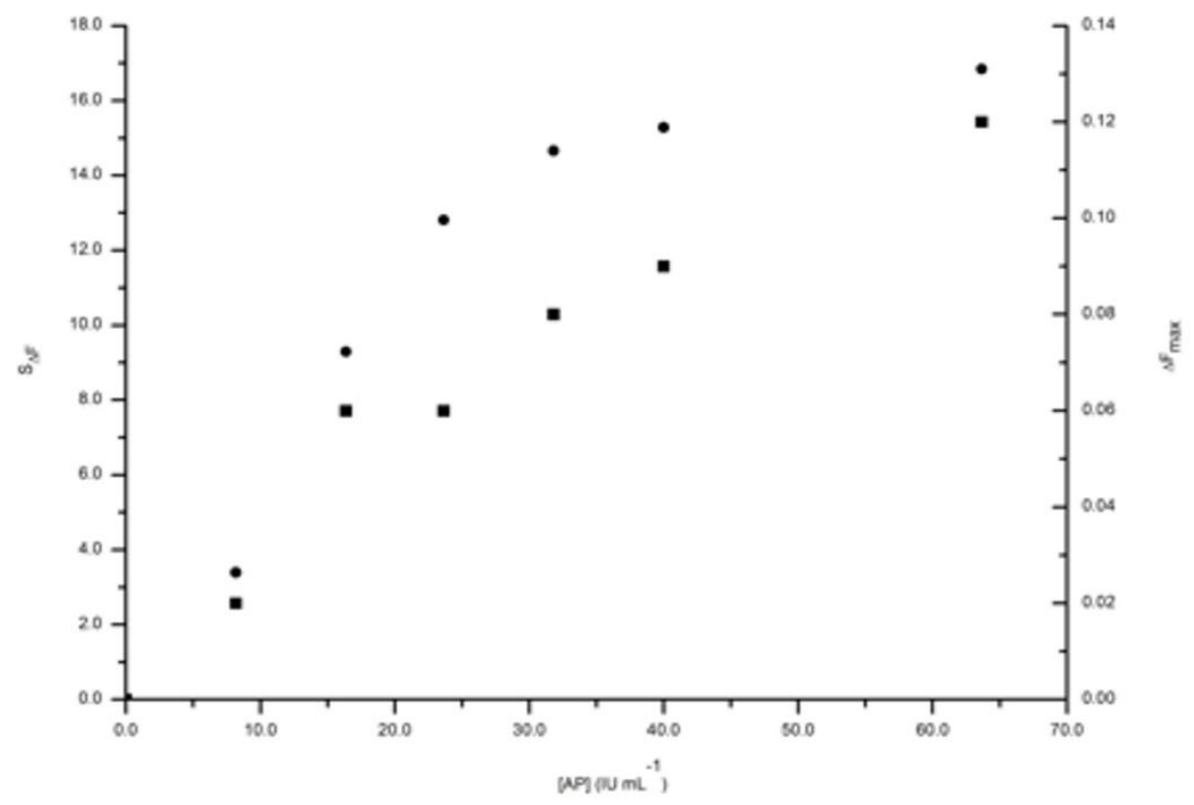

b.

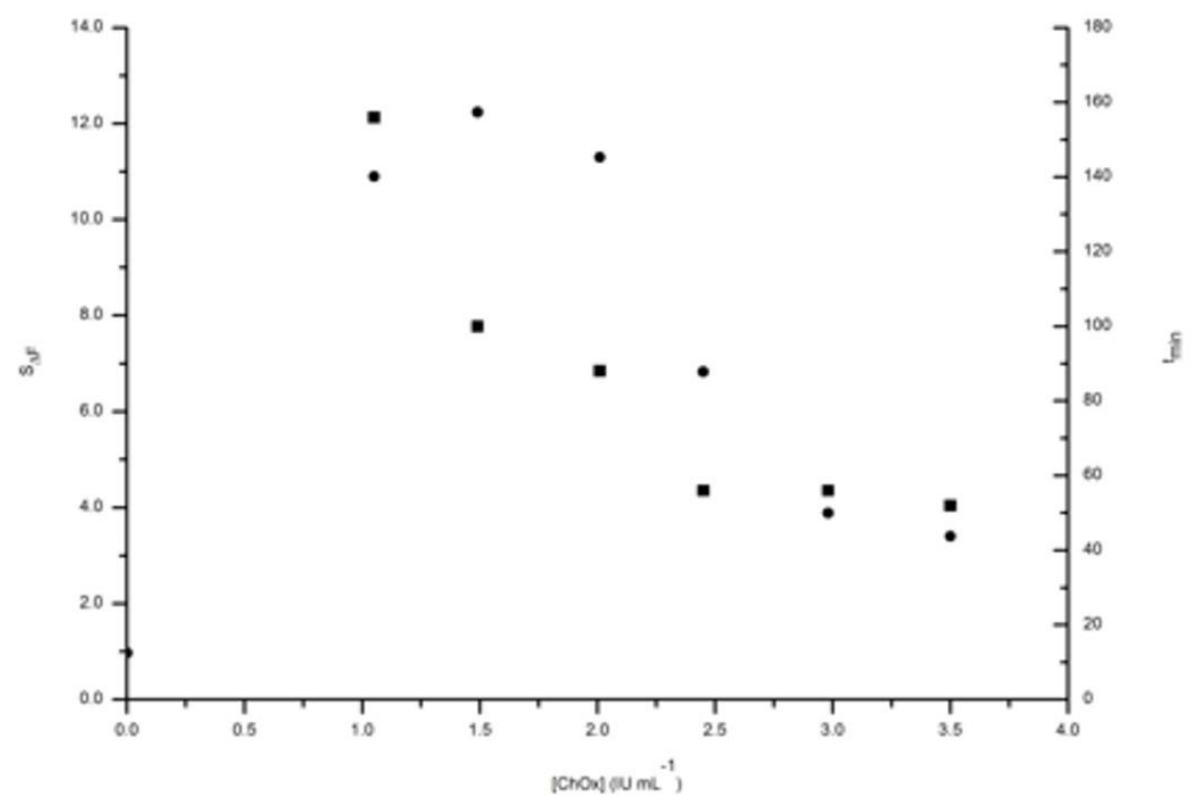

Figure 2 


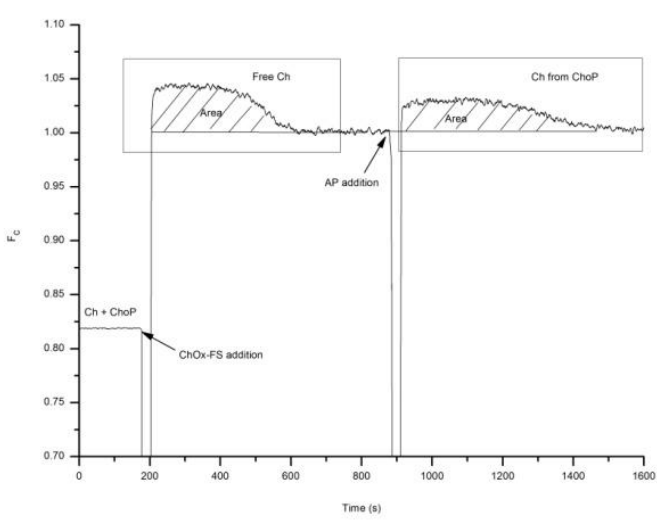

Figure 3

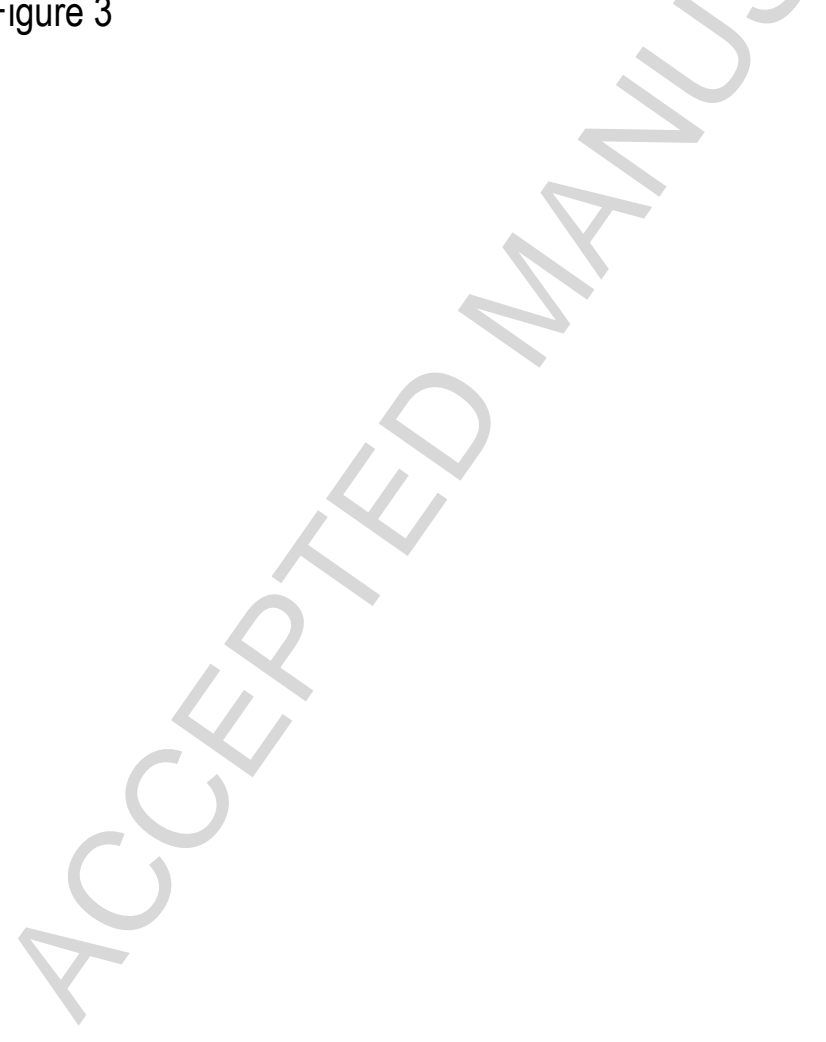




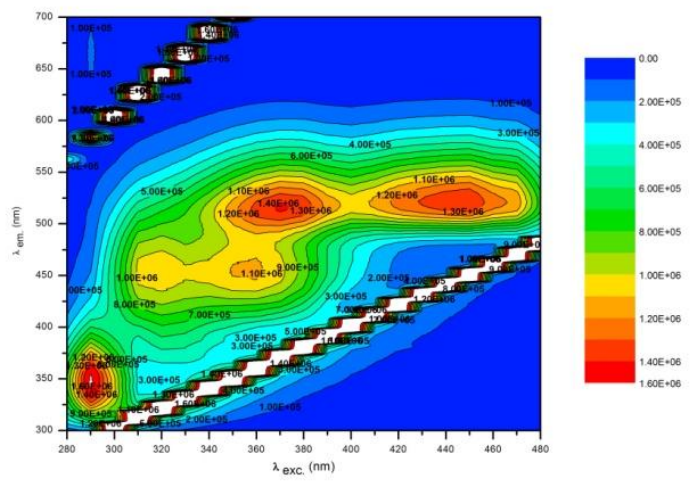

Figure 4 
Table 1. Influence of $\mathrm{pH}$ on $\mathrm{S}_{\Delta \mathrm{F}}\left(\bullet\right.$ and $\Delta \mathrm{F}_{\max }(\boldsymbol{\square})$. [AP] $=40 \mathrm{IU} \mathrm{mL} \mathrm{L}^{-1}$, [ChOx] $=1.65 \mathrm{IU} \mathrm{mL}^{-1}$, $[\mathrm{ChoP}]=1.00 \cdot 10^{-5} \mathrm{M}, \lambda_{\mathrm{exc}} .420 \mathrm{~nm}$ and $\lambda_{\mathrm{em}} .530 \mathrm{~nm}$.

\begin{tabular}{ccccc}
$\mathrm{pH}$ & 7 & 8 & 9 & 10 \\
\hline $\mathrm{S}_{\Delta \mathrm{F}}$ & 2.78 & 0 & 16.8 & 9.0 \\
$\Delta \mathrm{F}_{\max }$ & 0.011 & 0 & 0.105 & 0.042 \\
\hline
\end{tabular}


Table 2.- Figures of merit for $\mathrm{ChoP}$ and $\mathrm{Ch}$ determination using $\mathrm{ChOx}$ and/or $\mathrm{ChOx}-\mathrm{FS}$ fluorescence in the ChoP optimal conditions.

\begin{tabular}{|c|c|c|c|}
\hline & Calibration line ([ChoP] or [Ch] in M) & range (M) & RSD (\%) \\
\hline \multirow[t]{4}{*}{$\mathrm{ChOx}$} & $\mathrm{S}_{\Delta \mathrm{F}}=0.13_{( \pm 0.26)}+1.27_{( \pm 2.0)} * 10^{6}[\mathrm{ChoP}]$ & $5.2^{*} 10^{-7}$ to $1.0^{*} 10^{-5}\left(^{*}\right)$ & $3.7 \%(n=4)$ \\
\hline & $r=0.999$ & & \\
\hline & $\Delta \mathrm{F}_{\max }=0.003_{( \pm 0.001)}+1.34_{( \pm 1.42)} * 10^{4}[\mathrm{ChoP}]$ & $5.2^{*} 10^{-7}$ to $5.0^{*} 10^{-6}$ & $4.8 \%(n=4)$ \\
\hline & $r=0.993$ & & \\
\hline \multirow[t]{6}{*}{ ChOx-FS } & $S_{\Delta F}=0.47_{( \pm 0.35)}+2.41_{( \pm 2.0)} * 10^{5}[\mathrm{ChoP}]$ & $5.2^{*} 10^{-6}$ to $1.0^{*} 10^{-4}\left(^{*}\right)$ & $4.2 \%(n=4)$ \\
\hline & $r=0.999$ & & \\
\hline & $\Delta \mathrm{F}_{\max }=0.004_{( \pm 0.002)}+8.60_{( \pm 2.0)} * 10^{2}[\mathrm{ChoP}]$ & $5.2^{*} 10^{-6}$ to $1.0^{*} 10^{-5}$ & $5.0 \%(n=4)$ \\
\hline & $r=0.989$ & & \\
\hline & $S_{\Delta F}=1.96_{( \pm 1.5)}+1.57_{( \pm 1.0)} * 10^{5}[\mathrm{Ch}]$ & $9.2^{*} 10^{-6}$ to $1.0^{*} 10^{-4}\left(^{*}\right)$ & $4.1 \%(n=4)$ \\
\hline & $r=0.998$ & & \\
\hline
\end{tabular}

* Maximum concentrations tested. 


\section{HIGHLIGHTS}

- It has been developed a rapid method for determination of phosphorylcholine.

- Two enzymatic reactions are coupled in only one test.

- The fluorescence variation of Choline Oxidase is used as analytical parameter.

- The sequential determination of choline and phosphorylcholine is possible.

- A plate reader is used to measure the fluorescence with good results. 